\title{
Do corneas melt in the Scottish summer? A 10-year review of corneal perforations requiring cyanoacrylate gluing in theatre at a tertiary referral centre
}

\author{
Magdalena Edington $^{1} \cdot$ Julie Connolly ${ }^{1}$ David Lockington (i) $^{1}$ \\ Received: 1 October 2018 / Accepted: 8 October 2018 / Published online: 24 October 2018 \\ (c) The Royal College of Ophthalmologists 2018
}

Previous studies have identified the potential role of temperature and barometric pressure in contributing to a flare of inflammatory symptoms in susceptible rheumotological patients, but this association is controversial and not definitive $[1,2]$. Joint inflammation is due in part to the proinflammatory role of matrix metalloproteinases (MMPs); enzymes which also have a destructive role towards the corneal extracellular matrix [3]. We wanted to perform a 10-year review of corneal perforations requiring cyanoacrylate gluing in theatre at our university tertiary referral centre to assess for any seasonal association [4].

Patients who underwent emergency gluing procedures in theatre for corneal perforation at Gartnavel General Hospital, Glasgow between 2008 and 2017 were identified from theatre logbooks and their electronic records retrospectively analysed. Audit data included patient demographics, date of perforation, ocular co-morbidities and any associated systemic conditions.

There were 65 episodes in 43 patients of corneal perforation requiring gluing in this 10-year period. All identified cases were treated with application of cyanoacrylate glue. The majority of perforations $(27 / 43 ; 63 \%)$ occurred in patients $>60$ years of age, and of female gender $(25 / 43 ; 58 \%)$. Of the 43 patients, ten had an underlying systemic connective tissue disorder such as rheumatoid arthritis (RA) or systemic lupus erythematosus (SLE), nine had infectious keratitis, six had an inflammatory ocular surface (rosacea, ocular cicatrical pemphigoid, blepharitis), five were graft failures, three had corneal ectasias, seven fell into the 'other causes' category (including trauma, exposure, post-LASIK), and no clear cause was documented in three patients. There

David Lockington

davidlockington@hotmail.com

1 Tennent Institute of Ophthalmology, Gartnavel General Hospital, 1053 Great Western Road, Glasgow G12 0YN, UK were five patients who had three or more episodes of perforation; underlying diagnoses in these patients included Logic syndrome, SLE and rosacea keratitis.

There was a slightly higher incidence of corneal perforations in the spring and summer months (17 episodes in spring, 22 summer, 13 autumn, 13 winter). This association did not reach statistical significance (Chi-square $p=0.485$ ). With respect to those patients with underlying systemic connective tissue disorders, eight episodes occurred in the spring/summer months and eight in autumn/winter (see Figs. 1 and 2).

Average temperatures in Scotland range from 3 to 15 degrees Celsius $\left({ }^{\circ} \mathrm{C}\right)$, with mean and median temperatures of $9^{\circ} \mathrm{C}$. [See 'Scotland's Environment' from the Scottish Government, accessible at https://www. environment.gov.scot/media/1185/climate-climate.pdf].

We did not identify an increase in corneal perforations according to traditionally colder seasons in Scotland; rather, there was a slightly higher incidence in the spring/ summer. This was not statistically significant, possibly due to the small sample size and the lack of extreme temperatures between the Scottish seasons. We could not identify any reports linking weather conditions and corneal melting in the ophthalmic literature. Diseasemodifying anti-rheumatic drugs have previously been shown to improve the visual outcome in rheumatological patients with corneal melting, but this only implicates the presence of cellular inflammation, not the contributing factors for a flare in the underlying inflammatory condition [5]. A larger prospective study analysing these factors would be required to explore any link between seasonal variation and corneal melting leading to perforation.

Acknowledgements A version of this study was an oral presentation at the Scottish Ophthalmological Club, Stirling, Scotland in September 2017. 
Fig. 1 Graph illustrating number of corneal perforations requiring gluing by month of year from 2008-2017

Fig. 2 Clinical photographs illustrating use of cyanoacrylate glue in the management of corneal perforations, either as direct application or in association with a plastic disc (punched from the plastic drape by a skin biopsy trephine)
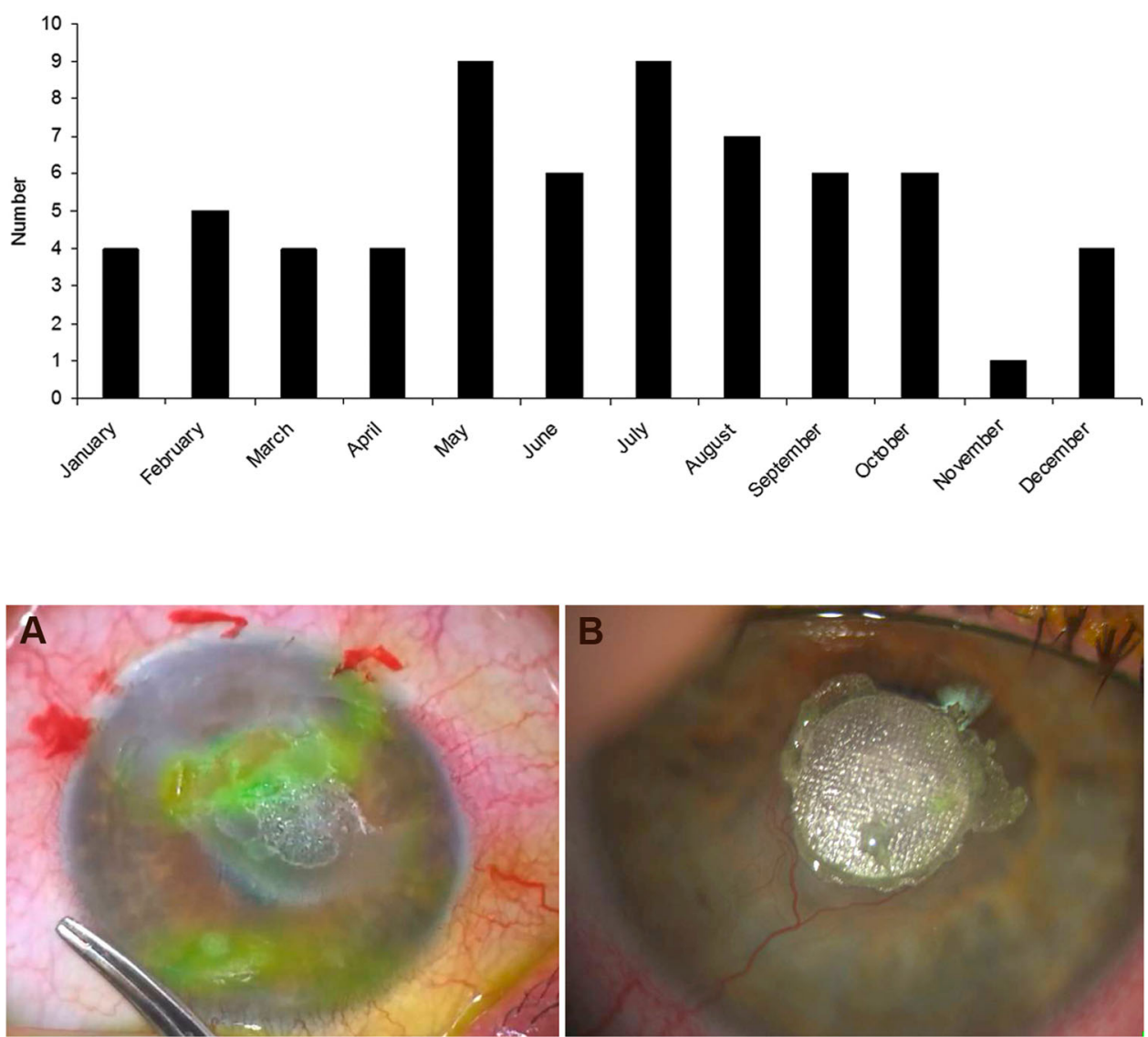

\section{Compliance with ethical standards}

Conflict of interest The authors declare that they have no conflict of interests.

\section{References}

1. Patberg WR, Rasker JJ. Weather effects in rheumatoid arthritis: from controversy to consensus. A review. J Rheumatol. 2004;31:1327-34.
2. Savage EM, McCormick D, McDonald S, Moore O, Stevenson M, Cairns AP. Does rheumatoid arthritis disease activity correlate with weather conditions? Rheumatol Int. 2015;35: 887-90.

3. Sakimoto T, Sawa M. Metalloproteinases in corneal diseases: degradation and processing. Cornea. 2012;31 (Suppl 1): S50-6.

4. Jhanji V, Young AL, Mehta JS, Sharma N, Agarwal T, Vajpayee RB. Management of corneal perforation. Surv Ophthalmol. 2011;56:522-38.

5. Saripalli L, Harrington TM, Notz RG, Torretti D. Corneal melt in rheumatic disorders: effect of disease-modifying antirheumatic drugs on morbidity. J Clin Rheumatol. 2005;11:134-9. 